\title{
LOST AND FOUND: A QUEST FOR SUSTAINABILITY AND RESILIENCE IN RURAL AREAS
}

\author{
DOI: 10.18485/arh_pt.2020.7.ch43
}

\section{_ Nataša Ćuković Ignjatović}

Assistant Professor, University of Belgrade - Faculty of Architecture, Bulevar kralja Aleksandra 73/II, natasa@arh.bg.ac.rs

\author{
_ Dušan Ignjatović \\ Associate Professor, University of Belgrade - Faculty of Architecture \\ Bulevar kralja Aleksandra 73/II, Ignjatovic.dusan@arh.bg.ac.rs
}

\author{
Nikola Miletić \\ PhD Student, University of Belgrade - Faculty of Architecture, \\ Bulevar kralja Aleksandra 73/II, nikolamiletic1994@gmail.com
}

\section{ABSTRACT}

Global trends of rapid and constant urbanisation are constantly revealing new societal, spatial and technological challenges, which naturally directs research focus towards urban areas. Urbanisation and imminent migrations, however, have significant repercussions on rural areas as well: exposure of tangible and intangible cultural heritage to decay, leading to extinction, can be identified as one of such processes that indirectly affect entire population, not only the scarce locals.

In the quest for sustainable proposals tailored for small and fragile communities with notable architectural and cultural heritage, the W.A.Ve Abroad Workshop explored sustainable models of revitalization of the village Bebića Luka in the vicinity of Valjevo in Western Serbia. During the workshop which was held in Belgrade, Bebića Luka and Venice in June and July 2018, architecture students from Belgrade, Venice and Ljubljana were analysing the multiple layers of Bebića Luka's present and past, trying to envision future scenarios and define adequate programmatic and design proposals. The workshop results included new models of activities, tailored to enable preservation of the tangible and intangible cultural heritage of the village through interactions between permanent and temporary residents, providing first-hand mutual exchange of specific knowledges. This process should expose local residents to some useful state-of-the-art concepts while directly transferring unique heritage of the village of Bebića Luka and the surrounding area to the visitors that will eventually return to urban areas. The workshop results were presented at IUAV University in Venice, during the final manifestations of the W.A.Ve 2018 Workshop in which more than 1500 students participated, which for the first time also included mentorship from teachers from five foreign universities.

The paper presents an overview of the methodological approach, derived concepts and design proposals for variety of interventions: from retrofitting the existing facilities to development of new complementary physical structures designed in accordance with principles of circular economy and sustainable development.

KEYWORDS _ cultural heritage, rural areas, sustainability, circular economy, resilience 


\section{INTRODUCTION}

As a consequence of global process of urbanization, cities have grown in size and influence, while rural areas have suffered negative social, economic and environmental impacts loosing its social capital to urban areas. The process of depopulation could, therefore, cause the disappearance of a large part of cultural tradition, which would consequently result in a 'poorer' and monotone society without recognisable identity and narrowed natural diversity (Lekic et al., 2018). Therefore, "rethinking" of rural areas is essentially a consideration of endurance, sustainable transformation therefore survival. Such transformation is crucial, as evidenced by a number of studies that seek opportunities for improving rural environments and preserving positive rural values (Wessely, 2019).

On the other hand, thanks to their marginalization and exclusion from the process of globalisation, rural areas have often maintained recognisable, sometimes unique identity. It is based on local culture and tradition, deriving from the specific social, natural, and artistic resources that otherwise would not have been preserved. This unique local spirit presents, at the same time, an important part of global human tangible and intangible heritage. One of the examples of such "pockets" is the case of a small village of Bebića Luka in Western Serbia, which was selected as the case study for "Wave Abroad - Belgrade" workshop.

The workshop gathered 15 architecture students from Belgrade, Venice and Ljubljana with tutors and guest lecturers from Faculty of Architecture - University of Belgrade and IUAV. During the first two weeks, the students worked in Belgrade with two-day field trip to Bebića Luka and nearby city of Valjevo and mount Medvednik. Final five days took place in Venice, where the presentation was completed and workshop results shared with other teams participating W.A.Ve 2018 workshop at IUAV, at the final exhibition.

\section{METHODS}

The search for Bebića Luka's cultural and formal identity and sustainability was carried out in two distinct phases: information gathering phase and design phase. Information gathering phase was conducted at the Faculty of Architecture in Belgrade and directly on site, aimed at recognising all the natural, historical, architectural, and cultural resources, as well as the immaterial heritage. Design phase was guided by the findings and conclusions derived from the information gathering phase, turning recognized potentials as well as weaknesses into developed set of spatial interventions. A brief one-day brainstorming session was used as a transition from the first to the second phase.

The information-gathering phase started with analysis of various available sources: maps, research articles and archives. Searching for, collecting and mapping all available information on Bebića Luka's natural (topographic, geographic, biological, hydrological), social (population, age structure), material (existing infrastructure, buildings, proximity to other centres) and cultural resources (tradition, beliefs), both on macro and micro levels has been performed in order to achieve a general overview of the current conditions and fragilities of the area. During this phase, a field trip was organised, in order to collect context-specific data, identify and analyse the current condition of the village. During this field trip, unstructured interviews were conducted with residents of Bebića Luka, allowing researchers to discover and understand how the locals perceive their community and use the resources they have. This relationship between the people and immediate environment is crucial in planning a sustainable and resilient community, as the Randolph T. Hester states, "it is the combination of how natural and cultural forces interact that provides essential pattern for resilience" (Hester, 2006).

Brainstorming session, organized immediately after the field trip, served as tool for synthesizing the results from the investigation phase and drafting the design guidelines for the design phase. Having considered contextual specificities and the natural-economic-cultural diversity that needs to be preserved, a list of priorities, barriers, potentials and goals was devised in order to develop a design scenario of self-sufficiency for the village and its territory, tailored to its needs. Design brief was 
drafted based on the identified processes, daily and seasonal activities, and multi-layered interconnections that formulate the local life style.

During the design phase, further research was carried-out for "fine-tuning" and retaining the identified authenticity as well as providing ground for achieving sustainability and resilience of the proposal. Various design programs, of different scales, were presented, tangling with both existing buildings and open spaces as well as with creation of new ones. The proposed scenario, aimed at reducing the weaknesses and promoting the local resources and with delicate approach to village's particularities is recognized as an approach that enables slow and sustainable change (Viola, 2018).

\section{BEBIĆA LUKA - "BACK TO THE LAND"}

Catching the interest of experts, locals, students and nature lovers for almost two decades, Bebića Luka is a small village within the municipality of Valjevo, situated about 500 meters above the sea level on the southern side of Mount Medvednik, along the Jablanica River (Figure 1). Established in the 1804. by four brothers that emigrated from the Lika region (Jankovic, 2009), it represents a traditional community organization of the 19th century's Serbian villages based on a family model. Bebića Luka literally means "the Bebić port".

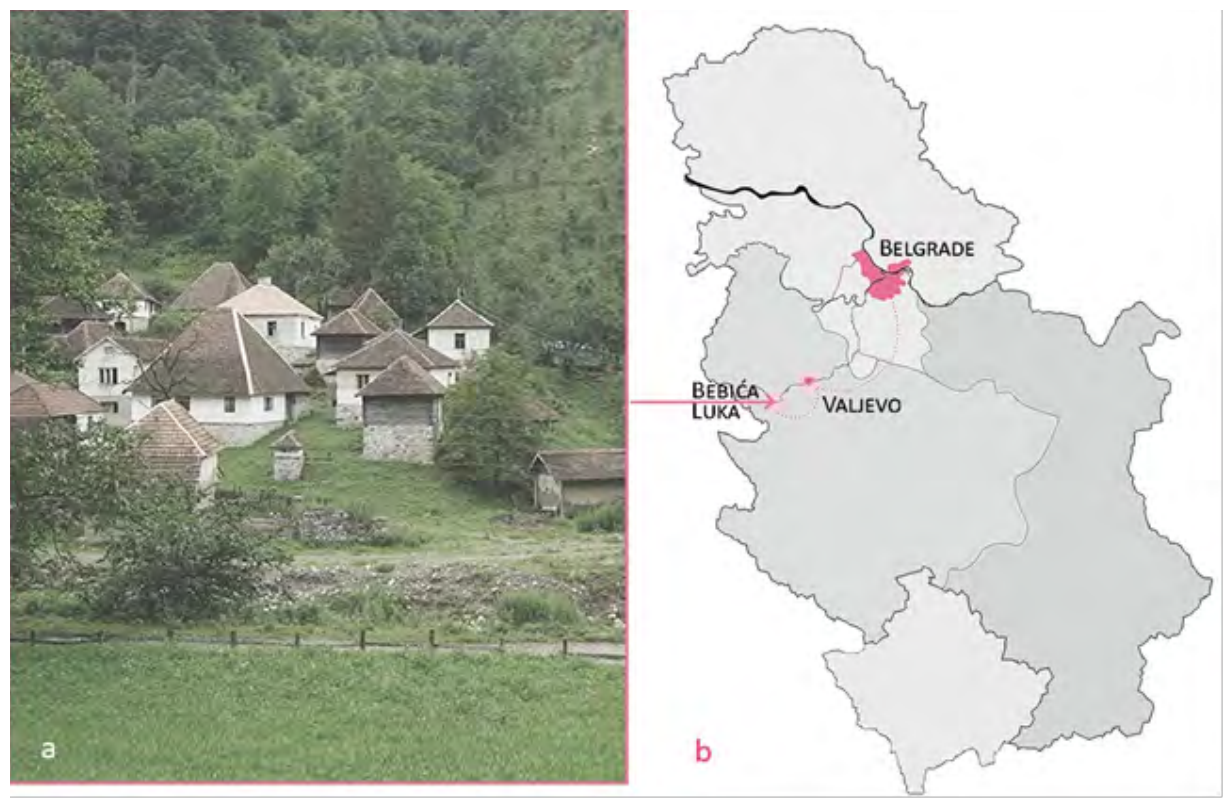

_ Figure 1 Bebića Luka - a) the village, b) its geographical position in Serbia (source: workshop presentation material)

Today the village represents a unique ambient set (Figure 1a) and is listed as cultural heritage and protected ethnic community. How people live there and how they earn their living has a strong connection with local culture and tradition thus representing intangible cultural heritage (Stevanovic and Drazic, 2016). Traditional architecture, unique building disposition, as well as furnishing, utensils and tools made from natural materials and traditional crafts are formulating specific material cultural heritage depicting this rural unit as unique in the Western Balkans.

The village has grown intensively providing, at its peak, for the needs of about a hundred inhabitants (Jankovic, 2009). As has been the case with many rural settlements, it has slowly decayed and today it has population of only seven inhabitants, all over the age of 60 . Well situated at the southern 
valley side, by the small river, surrounded by forests and fertile agricultural land, the village meets almost all of the requirements needed for achieving circular economy it once had, but is no longer able to maintain with its current demography. The village itself, but also the natural beauties of the area, climate and neighbouring sites of interest constitute a significant tourist potential (Garača et al. 2003) bringing new potential for sustainable development.

Despite of various favourable conditions for rural economy development, the village is now spatially isolated and its infrastructure lags behind the technological needs of modern agricultural production. The traditional economy based on the orchards and the livestock breeding have been abandoned and today is based exclusively on the cultivation of raspberries.

\section{DESIGN FOR SUSTAINABILITY, RESILIENCE AND PROSPERITY}

\section{Proposed activities}

Proposed activities primarily address the idea of repopulation which was identified as necessary precondition for authentic future development while making sure the tangible and intangible cultural heritage the village possesses is not lost. Functional reorientation of this village and its inhabitants towards the promotion of culture, natural lifestyle, tradition and life of the people during the 19th and 20th century has been seen by both the workshop and previous researchers as a possibility for stopping the economic decline and severe depopulation. Such reorientation is envisioned though the following set of activities:

_ Agro-tourism - Visitors do not just observe and consume the food, but they are taking an active part in its production and preparation, as if they were farmers themselves (Todorovic and Bjeljac 2009). This way, the residents get the necessary help while the visitors get a unique experience. The continuous presence of temporary residents can be seen as the new form of repopulation.

_ Traditional food production - With good climate and soil conditions as a potential, Bebića Luka can develop organic agriculture, which is the most sustainable method of food production in rural areas like this (Cizler, 2013). Proposed agricultural activities emphasize the regional and local particularities resulting from specific terrain, landscape and climate.

_ Local production and handcraft - These resources are an expression of authenticity and originality, becoming an important witness of the territorial identity. Studies reveal the importance of traditional farming systems and craftsmanship in contributing to the sustainability of rural areas making them more adaptive and resilient (Lekić et al, 2018).

_ Interactive workshops and courses - Knowledge sharing about local food production and traditional handcraft is used as a tool for enhancing the face-to-face interaction between the village's inhabitants and visitors from urban areas, and is giving meaning to the community, both local and visiting (Grimwade and Carter, 2000).

Design proposals

In order to realize planned activities, changes and additions to the physical structures in the village were proposed. The new structures - public spaces, shared facilities and accommodations are designed to support variety of planned activities and accommodate both residents and visitors - temporary residents (Figure 2):

_ Improving the residential and utility structures - Existing substandard houses are adapted and expanded to meet contemporary living needs of permanent and temporary residents; older structures are renewed and converted for accommodation and shared utility spaces; the most valuable structures are restored to their original form and function in order to preserve cultural heritage.

_ Improving the agricultural production - Creating a new productive landscape, vegetable and fruit orchards, to improve a self-sufficient local model of circular economy related to food production and energy management.

_ Creating public spaces - Simple open-air amphitheatre, placed on the natural slope in the 
centre of the village, for organizing public gatherings and cultural activities; market, a new covered multi-purpose space, adjacent to the village, embedded in the landscape as a new shared facility for daily and seasonal activities, as well as for some special events related to local production and agricultural education; network of small pedestrian paths and public spaces, connecting the villagers' houses and visitors' accommodation to newly formed sharing facilities, delicately responding to existing morphology.

_ Additional eco-based houses - New structures in the vicinity of the village planned to contain housing/accommodation (primarily for visitors) and shared spaces (for visitors and residents alike) having spaces of different levels of privacy - spaces for gathering the whole community, working in smaller teams, and individually.

\section{Design outcomes / Discussion}

The severe depopulation of Bebića Luka was addressed on several levels. The existing residential resources were expanded and improved to meet the contemporary needs of residents and visitors. New physical facilities and shared spaces (versatile in program and in use), such as eco-houses, market, amphitheatre and new paths and public spaces (Figure 2) are designed to facilitate social contacts, to encourage activities that would support the interactive relationship between the residents and the visitors/temporary residents.
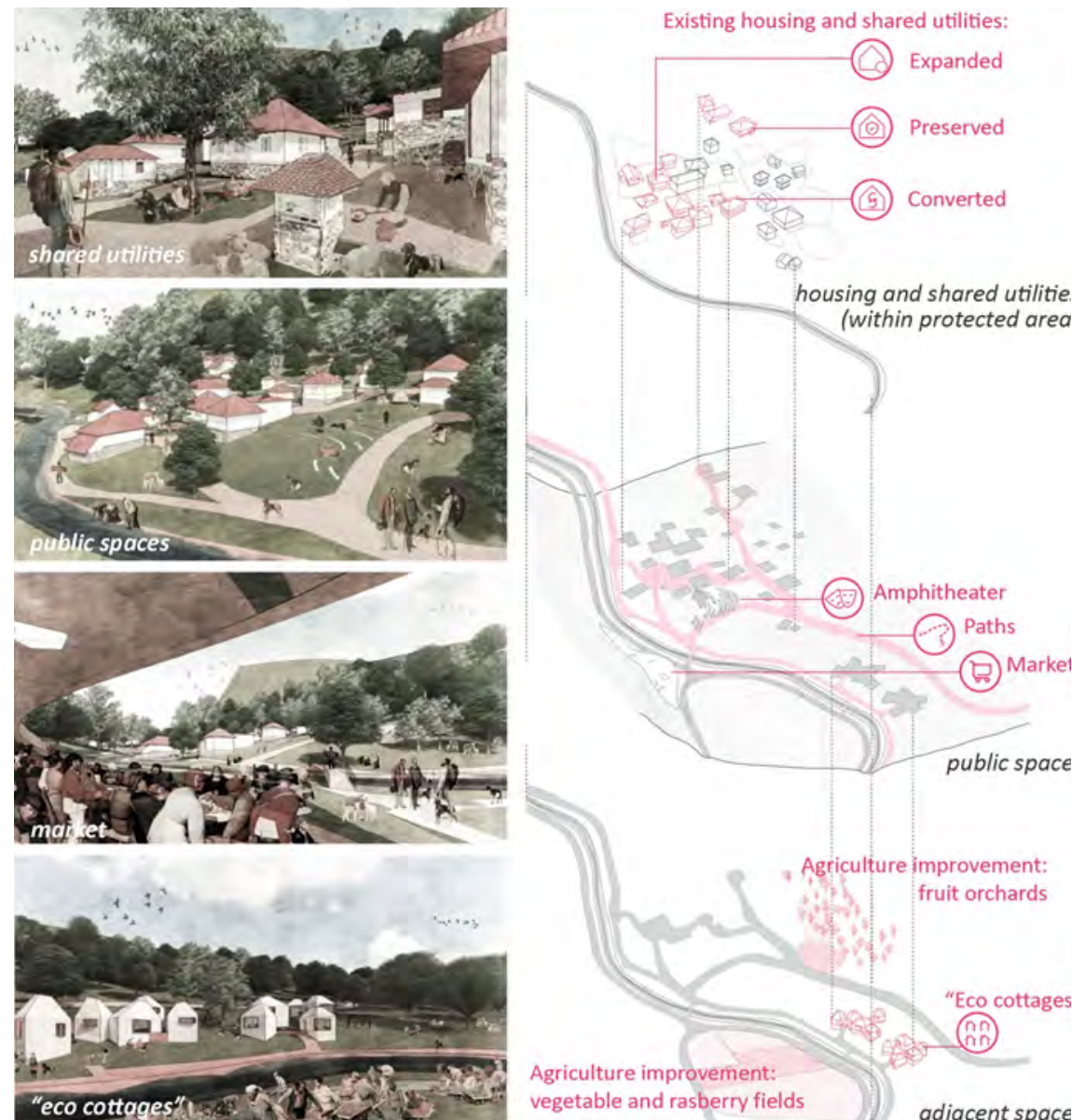

vegetable and rasberry fields

adjacent space 
Traditional agricultural production, as well as craftsmanship have great potential in achieving community sustainability (Berkes and Folke, 1994); they form the basis of social and economic regeneration, and can gradually develop as the village's human resources grow, providing for village's needs. Apart from economic, this type of production also has an educational aspect that can be utilized in developing agro-tourism.

Tourism is often perceived as a good way to strengthen local economy, protect the cultural heritage and develop community resilience. Still, we must consider that not all forms of tourism are compatible with fragile territories like Bebića Luka. Since tourism requires a transformation of the territory, it is necessary to reduce the anticipated risks. A possible strategy to introduce a slow and manageable change that ensures its resilience is community-based tourism, such as agro-tourism, which promotes the relationship between local community and visitors and involves the whole community in the shift of economy. This change could invert the depopulation trend, lead to improvement of transportation infrastructure between the village and nearby cities, and socioeconomic conditions of life (Viola, 2018).

The shared spaces, used for production and storage of home-made products and for traditional handcrafts (production and interactive workshops), are places designed to facilitate eye contact, physical closeness, equal access to work materials and information sources, encouraging people to listen to one another and to work together. Working together in such environment, actively engaging, exchanging knowledge, common experiences, customs, traditions and values, helps to preserve the intangible aspects of rural cultural heritage and identity. Lekić et al. provide a comprehencive overview of strategies and resarch findings regarding the sustainability of rural areas that strongly support this approach.

Material, architectural heritage is preserved by conserving and adapting the existing buildings and restoring the most valuable structures to original form and function. Village's ambient value, unique spatial disposition and density of authentic housing and utilitarian structures was preserved by development of new paths and open spaces with minimal impact on the landscape. Also, all new structures planned for the area outside the village centre, were designed in the way to blend in with the natural and man-made morphology and to have minimal ecological footprint, using sustainable technical innovative systems to minimize energy use. The workshop results can also be seen as a starting point for the development of a broader scenario (Anguillari, 2019), especially taking into account the recent changes in perception of quality and possibilities of permanent or temporary residing in rural areas.

\section{CONCLUSION}

Rural areas, despite their economic, social and infrastructural decline, in the contemporary theories of the sustainable development are seen more as a potential, than a problem, as is the case in our practice. Compared to the urban areas, the rural ones are offering direct contact with the natural environment coupled with cultural specificity of smaller community based on the traditional values and lifestyle. Rich cultural heritage, both material and immaterial one, is identified as one of the main values which should be enriched, developed and promoted in more diverse way creating the starting point for transformation of contemporary life pursuing the "lost" values which we have to "find" again.

This work provides insides into some of the activities and design proposals, developed during the three-week workshop "Wave Abroad - Belgrade". Results of the study are making the bases that should enable a new, contemporary and sustainable way of revitalising a specific fragile rural community.

Research addressed both natural and manmade resources, specific for Bebića Luka, considering the specific relationship between the people, their culture (crafts), the land and the natural environment as the main resource for their sustenance with an emphasis on a greater degree of self-suf- 
ficiency, autonomy and community life. The proposal aims at strengthening already present potentials identified as crucial for village's future development, through a set of socio-economic activities and physical interventions.

\section{REFERENCES}

_ Anguillari, Enrico. 2019. Back to the land. Conegliano: Anteferma Edizioni S.r.l. and Venice: Università luav di Venezia

_ Berkes, Fikret and Folke, Carl. 1994. "Linking social and ecological systems for resilience and sustainability" (Biejer Discussion Paper Series No. 52). Stockholm: Biejer International Institute of Ecological Economics, The Royal Swedish Academy of Sciences.

- Bertini, Viola. 2018. "Community Resilience and Tourism Development - The Case of Marginal Areas." in Sustainability and Resilience: Socio-Spatial Perspective, edited by Alenka Fikfak et al. 201-216. Delft: TU Delft Open.

- Cizler, Jasna. 2013. "Opportunities for the Sustainable Development of Rural Areas in Serbia." Problemy Ekorozwoju - Problems of Sustainable Development, Vol. 8, no 2: 85-91.

- Garača, V, Zdravković, Zorica and Stefanović, Nada. 2003 "Turistički potencijali sela Bebića Luka." Turizam 7: 49-51.

- Grimwade, Gordon and Carter, Bill. 2000. "Managing Small Heritage Sites with Interpretation and Community Involvement." International Journal of Heritage Studies, Vol. 6, no. 1: 33-48.

- Hester, Randolph T. 2006. Design for Ecological Democracy. Massachusetts: MIT Press.

- Janković, Dragana. 2009. "Zaustavljeno vreme _ Graditeljsko nasleđe - analiza seoskih kuća bondručara zaseoka Bebića Luka u selu Vujinovača kod Valjeva." in VREME arhitekture : Arhitektura i urbanizam u Valjevu 2004-2009: 62-71. Valjevo: Društvo arhitekata Valjeva i Izdavačko preduzeće Kolubara _ Lekić, Olivera, Gadžić, Nebojša and Milovanović, Anja. 2018. "Sustainability of Rural Areas _ Exploring Values, Challenges, and Socio-Cultural Role." in Sustainability and Resilience: Socio-Spatial Perspective, edited by Alenka Fikfak et al. 171-184. Delft: TU Delft Open

- Stevanović, Ksenija and Dražić, Tihomir. 2016. "Bebića Luka - Živi etno muzej." Kulturni predeo - VII Konferencija, 53-60. Beograd: Zavod za zaštitu spomenika kulture grada Beograda

- Todorović, Marina and Bjeljac, Željko. 2009. "Rural tourism in Serbia as a concept of development in undeveloped regions." Acta geographica Slovenica, Vol. 49, no. 2: 453-473.

_ Wessely, Heide. 2019. "The village is Dead! Long Live the Village!". Detail 9.2019: 22-31. 